\title{
MILITANTES SINDICALES EN JUJUY, ARGENTINA. UN ESTUDIO DEL COMPROMISO POLÍTICO DESDE LA PERSPECTIVA DE CARRERA
}

\section{UNION MILITANTS IN JUJUY, ARGENTINA. A STUDY OF POLITICAL COMMITMENT FROM A CAREER PERSPECTIVE}

\author{
Adrián Pablo Berardi Spairani*
}

RESUMEN

Este artículo analiza la militancia sindical en la provincia de Jujuy, Argentina, entre los años 2015 y 2017. El objetivo es dar cuenta de los elementos que condicionan y determinan el compromiso político de este tipo de militancia. Se trabajó con un enfoque microestructural y se recurrió a una metodología cualitativa a partir del relato de vida. Así, se pudo identificar que las carreras militantes comparten secuencias que son comunes, pero las prácticas políticas y las miradas respecto de su propia militancia difieren en tanto están condicionadas por sus espacios de participación.

PALABRAS CLAVE: ACTIVISMO * ARGENTINA * CARRERA MILITANTE * COMPROMISO POLÍTICO * SINDICALISMO

\section{ABSTRACT}

This article analyzes the union militancy in the province of Jujuy, Argentina between the years 2015 and 2017. The objective is to give an account of the elements that condition and determine the political commitment of this type of militancy. We worked with a microstructural jib and used a qualitative methodology based on the life story. It was possible to identify that militant career share common sequences, but political practices and views of their own militancy differ in that they are conditioned by their spaces of participation.

KEYWORDS: ACTIVISM * ARGENTINA * MILITANT CAREER * POLITICAL COMMITMENT * SYNDICALISM 


\section{INTRODUCCIÓN}

Desde la recuperación democrática de 1983 en Argentina se desarrollaron varios trabajos $^{1}$ vinculados a la militancia sindical. La mayoría se enfocó en un análisis macroestructural partiendo de dos ejes: 1) las transformaciones al interior de la Confederación General del Trabajo (CGT) y 2) el surgimiento de nuevos espacios de representación sindical. Ambas líneas de trabajo estuvieron marcadas por los cambios en los clivajes políticos.

El trabajo de Gordillo (2013) dio cuenta de las trasformaciones, fracturas y reunificaciones que atravesó la CGT a lo largo del Gobierno de Raúl Alfonsín (1983-1989), al prestar atención a las propuestas gubernamentales para desarrollar un mayor proceso de democratización al interior de los sindicatos, como la ley de "reordenamiento sindical", entre otras.

Por su parte, Schneider (2013) mostró la manera en que las ideas de trasformación del sindicalismo propuestas por el gobierno nacional terminaron por fortalecer las estructuras sindicales, que expusieron su capacidad política a partir de la protesta callejera, pero también del bloqueo al proyecto de ley de reordenamiento sindical por parte del Partido Justicialista (PJ) en el Congreso de la Nación. Schneider (2013) también analiza el rol del sector de la CGT, conocido como "el grupo de los 15", que mantuvo una postura de alianza, por un breve tiempo, con el gobierno radical e, incluso, ocupando sus principales dirigentes, el Ministerio de Trabajo Nacional.

Murillo (2013) y Schneider (2013) coinciden en la capacidad de veto del movimiento sindical, encolumnado en la CGT, a las propuestas de transformación de la organización sindical y a las políticas económicas. En este sentido, la CGT fue un actor clave para la reconfiguración del ps luego de haber sido derrotado por la Unión Cívica Radical (UCR) en 1983 (Palomino,

1 Entre otros Palomino (2000), Armelino (2004, 2005 y 2012), Pereyra (2008), Etchemendy y Collier (2008), Varela y Lotito (2009), Gordillo (2013), Murillo (2013), Schneider (2013) Abal (2011, 2015 y 2016), Varela (2013), Marticorena (2015) y Anigstein (2019).
2005) y su unidad fue fundamental para el triunfo de Carlos Saúl Menem (PJ) en las elecciones presidenciales de 1989.

Las reformas neoliberales aplicadas a principios de la década del 90 generaron nuevas transformaciones en el mundo sindical. Estos cambios no solo se vincularon al interior de la dirección de los gremios, sino también en las bases sociales de los sindicatos y su relación con el Estado y las estructuras partidarias, principalmente a partir del proceso de desocupación y precarización laboral que atravesó Argentina en el periodo neoliberal.

Los trabajos de Palomino (2000), Abal Medina (2011 y 2015) y Pereyra (2008) dieron cuenta del proceso de ruptura que atravesó la CGT a partir del alineamiento de distintos sectores del sindicalismo a las medidas económicas de corte neoliberal y los cambios en torno a las transformaciones dentro del mercado de trabajo, como la Reforma Laboral. De esta manera, se configuran dos sectores clave dentro de la cGT. Por un lado, un sector oficialista que acompaña las medidas gubernamentales $y$ cuyos dirigentes establecen un nuevo rol a partir de su participación en diversas empresas, configurando un sindicalismo empresarial (Abal Medina, 2011). Por el otro, un sector claramente opositor encuadrado en lo que se conoció como el Movimiento de Trabajadores Argentinos (мта) (Pereyra, 2008). Según el análisis de Palomino (2000), estos elementos llevaron a que las estructuras sindicales perdieran capacidad de acción, representación y reclutamiento.

Los trabajos de Armelino (2004 y 2005) analizaron el movimiento sindical dando cuenta del proceso de movilización y protestas generado en el marco de las transformaciones económicas y el surgimiento de nuevos sectores sindicales como el MTA y la Central de Trabajadores Argentinos (стA). Estos estudios permiten observar las fracturas generadas al interior del movimiento sindical, la emergencia de nuevos sectores de representación, el surgimiento de nuevos repertorios de acción sindical y la conformación de nuevas identidades político-sindicales. 
A partir del 2003, la militancia sindical fue analizada en torno a un nuevo ciclo de crecimiento económico como consecuencia del proceso de reindustrialización del país, aumento del empleo y nuevas demandas laborales. Una línea de trabajos se centró en la reconfiguración del sindicalismo en marco de los gobiernos kirchneristas (2003-2015), partiendo de dos líneas: por un lado, la idea de la revitalización sindical (Natalucci, 2013) y, por el otro, el neocorporativismo (Etchemendy y Collier, 2008).

Otros trabajos analizaron el surgimiento de nuevos espacios laborales a partir de la consolidación de un sector de trabajadores fuertemente precarizado. En este sentido, los trabajos de Varela (2013) y Varela y Lotito (2009) analizan la conformación de un nuevo sindicalismo de base, principalmente alineado a los sectores políticos de izquierda.

Desde otra perspectiva, Abal Medina (2016) analiza la conformación de la Confederación de Trabajadores de la Economía Popular (стЕP), que surge como representación de los trabajadores informales, muchos de ellos beneficiaros de programas y planes sociales.

Por otra parte, el trabajo de Anigstein (2019) dio cuenta de los vínculos entre la CGT $y$ los gobiernos kirchneristas, analizando las alianzas $y$ fracturas entre el sector sindical CGTista $y$ el gobierno. En tanto, Marticorena (2015) analizó la relación de la gestión kirchnerista con los distintos espacios sindicales, principalmente la CGT y la CTA. Finalmente, el trabajo de Armelino (2012) advierte las transformaciones que atravesó la CTA a lo largo del periodo kirchnerista (2003-2015), prestando atención a las fortalezas y debilidades de este sector sindical alineado con las políticas kirchneristas.

Respecto a las investigaciones sobre la militancia sindical en Jujuy, la mayoría de los trabajos se concentra en un tipo de análisis contextual de las problemáticas políticas y económicas. Los trabajos de Gómez y Kindgard (2006), Aramayo (2009), Lagos y Gutiérrez (2006), Kindgard (2009), Lagos y Conti (2010) y Ferrari (2014) dieron cuenta de la forma en que las transformaciones económicas desde la década del 70 comenzaron a impactar en el mercado de trabajo jujeño, al generar altos índices de desempleo en el sector privado $y$ un aumento sustancial del empleo estatal. Lo anterior generó la reorganización del sector sindical de los trabajadores públicos y dio lugar al surgimiento de un nuevo actor, el Frente de Gremios Estatales (FGE). Esos mismos estudios también mostraron las condiciones de aumento de la conflictividad social a partir de la década de los 90 , producto de la aplicación del neoliberalismo y el crecimiento de la desocupación que generó la emergencia de organizaciones de desocupados.

Finalmente, los trabajos de Kindgard y Gómez (1998), Gómez y Kindgard (2002), Iñigo y Gómez (2011) y Berengan, (2013) analizaron el ciclo de protestas en Jujuy y el surgimiento del corte de ruta como un repertorio de protesta novedoso.

Como se observa en estas investigaciones, la mayoría de los estudios abordó el análisis de la militancia sindical desde la recuperación democrática, utilizando un análisis a partir de una perspectiva macroestructural, prestando atención a los cambios en la estructura de representación sindical, los vínculos con el Estado y su rol en un contexto político económico. De esta manera, se puede notar un vacío respecto al análisis de las trayectorias de los militantes sindicales, principalmente en el contexto subnacional de Jujuy, Argentina.

Partiendo de esto, este trabajo propone analizar la militancia sindical a lo largo del periodo 1983-2015 en Jujuy, Argentina, desde una perspectiva microestructural a partir de un análisis procesual del compromiso político (Fillieule, 2001), al retomar la perspectiva de carrera propuesta por Becker (2012).

El objetivo principal es analizar la manera en que se conforma una carrera de militante sindical, prestando atención a los motivos que llevaron al involucramiento político y los elementos que condicionan o determinan el sostenimiento del compromiso a lo largo del tiempo.

La propuesta pretende recuperar los factores que dan cuenta de una carrera militante e indagar de qué forma los contextos políticos, las transformaciones en los clivajes y las estructuras de organización son factores clave para 
continuar o abandonar la militancia sindical. Este tipo de estudio permitirá comprender las diferentes etapas que atraviesa el militante e indagar los aspectos objetivos y subjetivos que constituyen su militancia.

El modelo de análisis procesual del compromiso, a partir del estudio de la carrera militante, se constituye como una herramienta novedosa para el estudio de la militancia ${ }^{2} y$ facilita su comprensión más allá de los espacios de pertenencia, olas de protestas o activismos específicos porque permite recuperar los sentidos que los propios militantes le dan a sus acciones (Agrikoliansky, 2017). Al ser la militancia un proceso dinámico (Fillieule, 2001), el estudio de la carrera militante permite abordar este tipo de actividad estudiando cada una de las secuencias que atraviesa el militante a lo largo de su trayectoria, considerando que cada etapa es consecuencia de la anterior y condición de la fase posterior (Becker, 2012). De este modo, se asume que la militancia no es necesariamente un proceso lineal, por el contrario, puede atravesar secuencias de discontinuidad (Agrikoliansky, 2017) y cambios que solo pueden ser percibidos a partir de un estudio biográfico del militante.

Así, la propuesta que aquí se presenta parte del supuesto que la militancia es un proceso que atraviesa continuidades y rupturas, al mismo tiempo que se encuentra fuertemente afectada por ciertos hitos producto de las transformaciones políticas y económicas.

Metodológicamente, se retoma una perspectiva cualitativa a partir de la técnica de la historia de vida, en tanto es un instrumento fundamental para recuperar los elementos a través de los cuales el militante hace comprensible su mundo (Meccia, 2012), las relaciones $y$ los entornos sociales en los que interviene (Meccia, 2015) y el contexto histórico en el que enmarca su narración (Della Porta, 2014). De esta manera, el recorrido biográfico que realiza el militante permite observar que el sujeto se

2 Existen algunos trabajos que abordaron la militancia desde esta perspectiva, entre otros, Vázquez (2010) y Berardi, A. (2017). constituye como el narrador de su historia y su sociedad (Saltalamacchia, 1987).

A partir de esto, en este artículo se analiza la carrera de tres militantes sindicales de la provincia de Jujuy, Argentina. Complementariamente, se utilizaron relatos de otros militantes sociales, partidarios y sindicales que forman el corpus de entrevistas realizadas en el marco de una investigación más amplia que se realizó en la provincia de Jujuy entre los años 2015-2017².

Las carreras militantes fueron seleccionadas partiendo de 1) los casos que alcanzaron un grado de dirigente en las organizaciones sindicales de pertenencia y 2) sus inicios militantes se producen en distintos periodos sociohistóricos, lo que permite comparar los contextos y clivajes diversos, así como sus miradas respecto a la realidad política de la provincia.

\section{APUNTES SOBRE EL CONTEXTO EN QUE SE INSCRIBEN LAS CARRERAS ${ }^{4}$}

Al igual que el contexto a nivel nacional, la provincia de Jujuy fue fuertemente afectada por el modelo de valorización financiera impuesto por el gobierno de facto (1976-1983) y por una importante expulsión de trabajadores del sistema productivo privado que fueron contratados por las estructuras estatales, lo que generó el crecimiento de más del $78 \%$ en la planta de trabajadores públicos de la provincia entre los años 1983-1989 (Aramayo, 2009).

A la crisis laboral y el deterioro del sistema productivo (Schorr y Golovanevsky, 2012), se sumó un contexto de alta inflación y fuerte endeudamiento, producto del aumento del gasto público generado por la absorción de mano de obra desocupada. Estos elementos dieron origen a un fuerte ciclo de protestas donde emergió, en 1988, el Frente de Gremios Estatales $(\mathrm{FGE})^{5}$, que se presentó como un nuevo espacio

3 Este trabajo presenta resultados parciales de una investigación sobre la carrera militante en Jujuy, financiada parcialmente por una Beca de Finalización de Doctorado, del Concejo Nacional de Investigaciones Científicas y Técnicas de Argentina.

4 Para una lectura más amplia del contexto en la provincia de Jujuy (1983-2015) ver Berardi (2017).

5 Integrado por el Sindicato de Empleados y Obreros 
de organización obrera con una importante capacidad de movilización (Aramayo, 2009). De esta forma, la crisis económica se asoció a una crisis política e institucional y como consecuencia del descontento y la protesta social, cuatro gobernadores se vieron obligados a renunciar entre 1990 y 1999, instalando un proceso de inestabilidad política e ingobernabilidad (Lagos y Conti, 2010; Belli y Slavutsky, 1996).

En los años 90, la falta de pago, el congelamiento de los salarios y los despidos fueron los ejes de las movilizaciones y protestas ${ }^{6}$ (Gómez y Kindgard, 2006). En tanto, las políticas de privatización de empresas estatales y el proceso de descentralización administrativa $y$ el traslado de las competencias (salud y educación) generaron un desequilibrio en la economía provincial (Oszlak, 1997). En ese contexto, el estado provincial comenzó a implementar un importante ajuste del gasto e inició un nuevo ciclo de endeudamiento público, mientras perdía capacidad para resolver la desocupación. El desempleo trepó y pasó del 6,5\% al 19,5\% entre los años 1993 y 2001 (Aramayo, 2009), mientras que el empleo estatal representó al 42,5\% de todos los asalariados de la provincia (Kindgard, 2009), pero al mismo tiempo cayeron los salarios y empeoraron las condiciones de trabajo de los empleados públicos.

Todos estos factores agudizaron las protestas. En noviembre de 1995, el FGE realizó un paro general masivo en la provincia; en junio de 1996 se llevó adelante la Marcha de la Dignidad (una movilización que unió San Salvador de Jujuy y La Quiaca reclamando el pago de salarios y el fin de los despidos, entre otras reivindicaciones) y entre mayo-junio de 1997 se

Municipales (SEOM), Centro de Educadores y Docentes de Enseñanza Media y Superior (CEDEms), Asociación de Trabajadores del Estado (ATE), Asociación de Docentes y Educadores Provinciales (ADEP), Asociación de Trabajadores de Sanidad (ATSA), Asociación del Personal Universitario de la Administración Pública (APUAP).

6 La tecnificación como la empresa Ledesma, el cierre de minas como Pirquitas y Pan de Azúcar, el achicamiento de la planta de trabajadores de Mina El Aguilar $y$ de empresas estatales como Altos Hornos Zapla, generaron el aumento del desempleo y los niveles de conflictividad inició un proceso de cortes de ruta masivos que estuvo marcado por la unidad del sector asalariado y la lucha que venían llevando adelante los trabajadores desocupados (Rodríguez, 2002). Si bien, los cortes se inician en Libertador General San Martín (departamento de Ledesma), en solo 6 días abarcaron a toda la provincia, a pesar de la política represiva puesta en marcha por el Estado Nacional y local.

El FGE articuló sus acciones con diferentes sectores de la sociedad, sobre todo con el sector desocupado que comenzaba a organizarse bajo la conformación de la Comisión de Desocupados y la Coordinadora de Piqueteros y Desocupados de la Provincia de Jujuy. Para ese entonces, la Multisectorial de Jujuy y la Iglesia Católica (Humahuaca y La Quiaca, donde incluso se creó la Comisión de Desocupados de La Quiaca liderada por el párroco Jesús Olmedo) también comenzaron a tener un lugar en las movilizaciones.

El ciclo de protestas dio origen a otras organizaciones de desocupados como el Centro de Desocupados y Desempleados del Departamento Ledesma, la Corriente Clasista y Combativa (ccc), la Central de Trabajadores Argentinos (СтA) -integrada por trabajadores ocupados y desocupados-, que no solo aglutinaban importantes liderazgos (como Carlos "Perro" Santillán, Milagro Sala o Fernando "Nando" Acosta), sino que daban cuenta de una importante organización de los sectores populares de la provincia y sostenían una importante base de organización sindical.

Para el año 1999, el triunfo electoral del justicialista Eduardo Fellner logró dar por terminado el ciclo de inestabilidad política y estableció un reordenamiento político, sin embargo, la efervescencia de las movilizaciones y protestas se sostuvo (Lagos y Conti, 2010). Incluso aparece con fuerza otro actor, la Organización Barrial Tupac Amaru ${ }^{7}$, constituida inicialmente como una pata barrial de la СTA, que tendrá un rol clave como agente de protestas en la década del 2000.

$7 \quad$ Sobre este tema ver Moscovich (2009) y Battezzati (2014). 
Entre los años 2003 y 2006, según Aramayo (2009), el desempleo cayó un 13\%, favorecido por la asignación de recursos provenientes del Estado Nacional a partir de distintos programas o planes sociales, que en cierto punto generó un aumento de la informalidad (Abal, 2016) y el incremento del empleo público provincial.

Durante el periodo 2003-2015, el empleo público siguió siendo el mayor motorizador de la asalarización en la provincia, junto con el comercio. Sin embargo, las características de ese tipo de empleo sostenían los bajos salarios $y$ altos niveles de precarización laboral (Ferrari, 2018). Así, las principales protestas fueron encabezadas por los sindicatos de empleados púbicos, principalmente ATE y SEOM. En el ámbito privado, los principales conflictos laborales se generaron en la empresa Ledesma y las protestas fueron lideradas principalmente por el Sindicato de Obreros y Empleados del Azúcar del Ingenio Ledesma (SOEAIL), con demandas salariales $y$ de condiciones laborales.

Finalmente, si bien no es algo de lo que se ocupa este artículo, la Tupac Amaru fue sin duda el actor de mayor beligerancia en la provincia dirigiendo sus demandas, por recursos y programas sociales para los sectores informales de la economía y los desocupados, al gobierno provincial.

\section{CARRERAS DE MILITANTES SINDICALES}

La militancia en el ámbito sindical se diferencia de otros tipos de militancias porque su inscripción está determinada por el ámbito laboral, es su lugar como trabajador lo que determina las condiciones de posibilidad de este tipo de carrera militante. Entonces, el cambio de empleo (principalmente de rubro de actividad), lleva a que el militante cambie también el gremio en que desarrolla su práctica política. Sin embargo, la militancia sindical no niega vínculos o prácticas políticas en otros ámbitos de militancia, como se muestra en las carreras que aquí se presentan, los militantes sindicales en muchos casos se vinculan a otros espacios de militancia no gremiales, como partidos políticos y sindicatos.
Lisandro nació en Jujuy en 1956, es profesor preuniversitario de Física y Matemática y se formó como técnico en mina. En 1977, comenzó a trabajar en Altos Hornos Zapla ${ }^{8}$ y con la recuperación democrática en 1983 empezó a militar en la Asociación de Supervisores de la Industria Metalmecánica de la República Argentina (ASIMRA), donde fue elegido por sus compañeros como delegado de fábrica. En 1991, en el marco del proceso de privatización, aceptó el retiro voluntario y se volcó a la docencia. Se involucró en el Centro de Docentes de Enseñanza Media y Superior (C.E.D.E.M.S) de Jujuy y más tarde en la Asociación Docentes e Investigadores de la Universidad Nacional de Jujuy (ADIUNJu), donde llegó a ser electo Secretario General. Sin embargo, su compromiso político no empezó en el sindicalismo, sino en la militancia estudiantil mientras estudiaba en la provincia de San Juan. Para él, ese primer acercamiento a la militancia fue compartir espacios con "los muchachos que jugábamos al rugby", aunque asume que mantenía cierto acercamiento al PJ.

Martina nació en Jujuy en 1960. En la década del noventa comenzó a trabajar en el Sindicato de Obreros Panaderos Unidos de Jujuy (OPUJ), y quizás influenciada por un tío que militaba en el Sindicato de Gráficos de Buenos Aires, empezó a militar en la Unión de Trabajadores de Entidades Deportivas y Civiles (UTEDyc) de Jujuy. Se integró al entramado institucional del gremio y llegó a ser Secretaria General. Además, formó parte de la Comisión Directiva de

8 Altos Hornos Zapla (Aceros Zapla S.A. actualmente) se fundó en 1943 y perteneció a Fabricaciones Militares hasta su privatización en 1993. Ubicada en el departamento de Palpala (a 13 kilómetros de la capital provincial), fue organizadora social y económica de la ciudad, a tal punto que se creó la Asociación Cultural y Deportiva Altos Hornos Zapla. Luego de su privatización solo quedaron 709 de los 2560 trabajadores (Bergesio y Golovanevsky, 2010). La organización de los trabajadores está dividida en cinco gremios: Asociación de Supervisores de la Industria Metalmecánica de la República Argentina (ASIMRA), Asociación Trabajadores del Estado (ATE), Unión de Obreros Metalúrgicos (UOM), Unión Personal Civil de la Nación (UPCN) y Sindicato Único de Altos Hornos Zapla. 
las 62 Organizaciones Peronistas, una fracción de la Confederación General del Trabajo (CGT). Pero su involucramiento militante tiene otro origen, antes de comenzar a participar en la UTEDyc tuvo un paso por la militancia social en el Centro Vecinal "200 viviendas", en el barrio de Alto Comedero, en la capital jujeña.

Maite nació en Jujuy en 1982, graduada como licenciada en Comunicación Social, en el año 2007 comenzó a trabajar en el sector de prensa del Instituto Nacional contra la Discriminación, la Xenofobia y el Racismo (INADI) y comenzó a militar en la Asociación de Trabajadores del Estado (ATE). Trabajó en la Secretaría de Derechos Humanos y en una escuela pública provincial; en todos sus trabajos fue delegada sindical y en 2015 fue electa secretaria de Comunicación del gremio. Además, es militante de la Organización Hijos e Hijas por la Identidad y la Justicia contra el Olvido y el Silencio (H.I.J.o.s.) Regional Jujuy. Sus comienzos militantes se remontan al año 2005 , cuando se incorpora a la militancia social en la Organización Juanita Moro, principalmente en la difusión de actividades y en el trabajo de alfabetización.

Lisandro comenzó su militancia sindical en un momento particular de la provincia, la recuperación de la democracia vino acompañada de una fuerte crisis económica y el inicio de un importante ciclo de protestas que se mantuvo vigente por casi dos décadas. Lisandro se acuerda de esas protestas, pero no formó parte de ese colectivo de trabajadores ni participó en las manifestaciones en la década del ochenta:

A mediados de los ochenta se empieza a pudrir todo, mi mujer que era maestra podía participar [de las protestas] pero yo estaba todo el día en la fábrica [...] pero a fines de los ochenta se empezó a pudrir todo en Zapla (Lisandro, comunicación personal, junio de 2015).

Durante los años 80, Lisandro participó de distintas discusiones en torno a los salarios $y$ condiciones de trabajo en la fábrica, pero no da cuenta de altos niveles de conflictividad al interior de la planta. Esta situación cambia a finales de la década, cuando en pleno conflicto económico en la provincia deciden con otros compañeros conformar una lista opositora a la conducción del gremio.

La propuesta era no solo luchar por sus condiciones, sino integrar el plan de lucha de los trabajadores estatales de la provincia. Sin embargo, las autoridades del sindicato les pidieron mantener la unidad del gremio, no era momento de divisiones; ante las distintas presiones y amenazas por parte de los dirigentes del sindicato, desistieron de conformar una lista alternativa a la conducción del gremio: "ahí dije, chau me voy" (Lisandro, comunicación personal, junio de 2015).

Patricio, ex delegado del Sindicato Único de Trabajadores de Altos Hornos Zapla en el momento de la privatización, también recuerda la manera en que la conducción de los gremios negociaba a espalda de los trabajadores:

Los gremios tenían acuerdos con la patronal, quienes manejaban la empresa eran los militares, $y$ los dirigentes de los distintos sindicatos iban a negociar con ellos a Buenos Aires. Después venían con todo cocinado, por supuesto a favor de la empresa. [...]. Y con la privatización todo se fue al tacho. (Patricio, comunicación personal, marzo de 2017).

El proceso de despidos en los sectores productivos en la provincia constituyó un punto clave de la crisis político institucional, pero también un cambio fundamental para algunos sectores del movimiento sindical de la provincia. Para Lisandro, la privatización de Zapla fue un quiebre en su carrera militante, la forma en que los gremios pactaron los despidos constituyó un acontecimiento que lo marcó como trabajador y como militante. Cuenta que los argumentos para los despidos fueron diversos, hasta que los propios dirigentes que apoyaron la privatización fueron despedidos o jubilados anticipadamente:

Cuando llegaron para privatizar dijeron que tenían que quedar 1200, éramos 2800 más o menos, entonces como 'buenos luchadores', empezamos a ver el que era tuerto, el rengo, el que chupaba, el 
que le pegaba a la mujer, y quedamos los 1200 rubios, de ojos celestes, alemanes. Cuando llegaron los nuevos dueños dijeron 'no son 1200 , son 800 ', 'che, pero... somos los paladar negro', a la mierda los paladar negro. Entonces ahí empezás a ver la bajeza de la gente, cómo los que hasta ayer eran compañeros te matan sin ningún problema, entonces opté por irme, porque yo tenía la suerte de que podía hacer otras cosas, había gente en la fábrica que estaba limitada a la fábrica. (Lisandro, comunicación personal, junio de 2015).

Lisandro se fue de Altos Hornos Zapla con un retiro voluntario y comenzó a trabajar como docente preuniversitario. Lo anterior, significó un cambio en su ámbito laboral y modificó su espacio de militancia cuando se integró al gremio docente C.E.D.E.M.S., donde llegó a ser secretario gremial.

En los años 90, la militancia sindical docente se constituyó en uno de los focos de resistencia de las políticas neoliberales: la reducción del porcentaje de PBI en educación, la descentralización y la Ley Federal de Educación (que en Jujuy se puso en marcha por medio de Ley General de Educación) fueron causas centrales de las protestas de los docentes. En Jujuy, la lucha de los docentes estuvo asociada a las del resto de los trabajadores estatales, $y$ sus gremios, entre ellos, el C.E.D.E.M.S., integraron el FGE.

Para Lisandro, su cambio de espacio de militancia también significó "poder pelear distinto", ya no eran acuerdos al interior de la fábrica, la militancia sindical docente se integró al plan de lucha de todos los trabajadores estatales y municipales. Así, su militancia era luchar por transformación política. La capacidad de movilización $y$ de solidaridad de los trabajadores estatales son, desde su mirada, clave para interpretar la militancia sindical del momento, pero, también, dan cuenta de que la organización y la capacidad del movimiento sindical no se logró plasmar en un programa político.

Y ahí empezamos unos años de mierda, porque estuvimos prácticamente durante 10 años jodiendo, peleando, luchando, cortando, echando gobernadores, sin poder avanzar, sin poder cristalizar lo que era obvio que se podía hacer desde lo sindical, desde lo sindical vos podías definir cosas, pero no las podías cristalizar políticamente. (Lisandro, comunicación personal, junio de 2015).

Raúl, ex secretario general de ATE Jujuy y referente del FGE, sostiene:

Nosotros tenemos la idea del poder como verbo, querer hacer [...] bancándose lo que hay que bancarse, poniendo primero el cuerpo, [...] lo hay que hacer es lograr sintetizar lo que la gente quiere, lo que los compañeros quieren, [pero] cuando se intentó hacer no tuvo la expresión [en el plano político electoral] de lo que realmente significaba la lucha social. [Porque en cierto punto] el Estado pasa a ser un enemigo, es el que te cobra impuestos $y$ el que te baja el salario. (Raúl, comunicación personal, junio de 2015).

En los años 90, Martina empezaba su militancia en UTEDyc. Ella cuenta que hay dos razones por las que empezó a militar en el gremio. La primera fue su experiencia como militante social en un centro vecinal mientras estudiaba una Tecnicatura en Administración de Organizaciones No Gubernamentales, porque la llevó a darse cuenta que quería "ser una persona útil a la sociedad". La segunda fue su experiencia como empleada de opu donde comenzó a desarrollar un importante conocimiento sobre legislación y derechos laborales: "Ahí me metí en el gremio, me fui interiorizando, participaba en las asambleas que hacían acá en el sindicato, en las reuniones de comisión directiva." (Martina, comunicación personal, septiembre de 2016).

Martina no pasó por la etapa de delegada del lugar de trabajo, sino que inmediatamente se integró a la estructura de la conducción del gremio:

Pasé a ser secretaria gremial, así que ya ahí me empecé a mover con el tema de inspecciones [laborales], empecé a aplicar 
un poquito lo que yo veía que acá por ahí no se hacía, y bueno, a interiorizarme más con el tema. Luego fui secretaria de Hacienda, también nos permitía conocer más cosas, o sea, estaba dentro del sindicato $y$ viendo todo lo que los compañeros acá necesitaban y todo lo demás, y después Dios me dio la posibilidad de poder estar hoy al frente [como secretaria general]. (Martina, comunicación personal, septiembre de 2016).

A diferencia de Lisandro, la actividad militante de Martina no se encuentra en el espacio público ni plantea un programa de trasformación política. Así, su militancia está centrada en defender los derechos de los trabajadores. Ella afirma que el gremio no usa la misma estrategia que los sindicatos de trabajadores estatales de la provincia porque no tiene la capacidad de movilización que tienen ellos. No obstante, sostiene que tienen una ventaja porque al ser la UTDyc el representante de la población trabajadora, por ejemplo, los gremios, su capacidad de negociación logra resultados sin necesidad de llegar a una acción directa:

Recuerdo que discutiendo con el secretario adjunto de un gremio docente le dije `me despedís uno y te quemo gomas frente al gremio, así de simple, despedime uno y te quemo gomas' y le corté y quedó; pregúntame ahora si me despidió uno, no me despidió ninguno. [pero] en Jujuy no he llegado [a eso] pero creería que si se tiene que dar se va a dar en un gremio, $[y]$ es muy vergonzoso y bochornoso que un sindicato tenga que ir a quemarte gomas $y$ hacer una movilización porque otro sindicato no cumple lo que dice el convenio de UTEDYC. (Martina, comunicación personal, septiembre de 2016).

Las diferentes estrategias que plantea cada uno de los gremios están marcadas por sus experiencias $y$ aprendizajes, pero eso no significa que el contexto no haya influenciado en el compromiso político. Según Martina, su involucramiento político va más allá del sindicato y no siempre la conflictividad es el camino para el cambio. Esta afirmación tiene un sentido, después de integrar la UTDyc, Martina se involucró en la militancia en el partido Justicialista en la localidad de Purmamarca, de donde es oriunda. En dicha región, desde hace unos años, ella venía trabajando con los "vecinos" para mejorar la calidad de vida, por ejemplo, lograr la conexión de gas en algunas zonas semirrurales. Esto le permitió entablar vínculos con las estructuras burocráticas e institucionales, generando redes de intercambio y siendo reconocida por los otros.

Maite comenzó su militancia sindical en los años 2000, su involucramiento —al igual que Lisandro y Martina - se vinculó a su espacio laboral, pero en su caso las condiciones de trabajo fueron clave.

En 2007 yo me afilio a ATE; yo trabajaba en el INADI, en Prensa, $y$ empecé a tener problemas con mi jefa, estábamos en negro, había varios problemas digamos. Entonces me acerqué a ATE, yo ya conocía ATE desde antes, porque estaba haciendo un documental sobre la historia de ATE Jujuy. (Maite, comunicación personal, junio de 2015).

Para Maite, el maltrato laboral, los bajos salarios y la forma irregular de contratación son causas de su involucramiento gremial, pero no reniega que su experiencia en la militancia social en la Organización Juanita Moro, fue un punto de quiebre en su compromiso político.

Lo interesante de la carrera militante de Maite es que, incluso, en el periodo que no fue empleada estatal, mantuvo su actividad militante en ATE, principalmente en el sector de prensa.

Después dejo de trabajar en ese lugar [INADI] porque tenía que terminar mi tesis para la Licenciatura. [Pero] en el 2011 me hablan los chicos de Prensa, de ATE [...], para decirme si quería laburar en ATE, en Prensa. [...] Les dije que sí, [y] después me fui metiendo en ATE. (Maite, comunicación personal, junio de 2015). 
Desde su mirada, al igual que en el caso de Lisandro, los niveles de movilización del gremio jugaron un factor clave para su compromiso. Según ella, fue todo sui géneris donde su participación y experiencia en las protestas del gremio a lo largo de los años 2000 fueron fundamentales:

Yo venía con el tren de militancia activa, ATE es así todo el tiempo, es activo, [...] porque hay un montón de cosas para hacer, $y$ cuando uno le agarra, viste, empezás y empezás, $y$ es un gremio que ha estado siempre en la calle, acá en Jujuy siempre se ha caracterizado por ser el gremio más combativo, digamos....[...] cuando ves la lucha de los compañeros a uno le pasan adentro, en el corazón, no encuentro otra razón. (Maite, comunicación personal, junio de 2015).

Tanto para Maite como para Lisandro, las protestas $y$ las manifestaciones constituyeron entonces un elemento persuasivo y motivacional de su militancia. La protesta fue para ellos un espacio de socialización política, de aprendizaje e influencia para el compromiso político (McAdam, 1982 y 1988). En sus carreras militantes, la manifestación aparece, como sostienen Fillieule y Tartakowsky (2015), como un lugar donde:

...los individuos negocian las significaciones originadas en la interacción con el prójimo. Por consiguiente, el compromiso en una actividad manifestante es un momento en el que se pone en juego $-y$ por lo tanto se aprende- un repertorio de conductas militantes instituidas (p. 126).

Por otra parte, durante los 2000, muchos militantes de los sectores de desocupados, que recibían algún programa o plan social con prestaciones en el Estado, se afiliaban a ATE, generando un aumento sustancial de sus miembros. Según el secretario adjunto de ATE Jujuy, el gremio pasó de representar a 7000 trabajadores en 2007 a más de 17000 en el año 2015. Pero, al mismo tiempo, muchos de esos afiliados comenzaban a militar en el gremio.
Así lo comenta Lucas, militante de la Corriente Clasista y Combativa de Jujuy e integrante de la agrupación Tito Galle en ATE:

Nosotros teníamos unos programas de capacitación, dependíamos del Ministerio de Educación, teníamos que planificar todo el desarrollo de la capacitación [...], dentro de la ccc en 2012 pusimos en debate si nos afiliábamos o no al gremio, si formábamos un gremio propio o cómo hacíamos para sostener este trabajo precarizado, [...] decidimos armar una agrupación, para estar dentro de ATE, porque entendimos que éramos trabajadores del Estado. (Lucas, comunicación personal, septiembre de 2016).

Así, la capacidad de movilización y protesta social de ATE generó canales de persuasión (Klandermans, 1984) para la continuidad de su compromiso, incluso en momentos donde su espacio laboral no era estatal, que encontró en ATE su espacio de pertenencia.

Al igual que Martina, Maite constituyó un doble compromiso cuando se vinculó a la militancia social en la organización H.I.J.o.s., a pesar de no ser víctima directa del Terrorismo de Estado. Para ella, su doble militancia es totalmente compatible, incluso, en el momento de la entrevista ATE e H.I.J.o.s. eran la querella de trabajadores estatales desaparecidos durante la última dictadura cívico militar.

En los tres casos se puede observar que el acercamiento a la militancia sindical está marcado, y es casi una condición ${ }^{9}$, por la pertenencia al espacio laboral. Sin embargo, los tres tuvieron una experiencia de activismo o militancia previa que se inscribe en un proceso inicial de socialización política (Passy, 2002). Por otra parte, en los tres militantes los procesos de aprendizaje también constituyeron factores de compromiso, aunque en el caso de Maite y Lisandro, la protesta y la movilización

$9 \quad$ Este trabajo no puede afirmar que existan militantes sindicales que no estén relacionados a los trabajadores que representa el sindicato en el que desarrollan sus actividades. 
social juegan un rol fundamental, al proyectar su actividad política desde el gremialismo.

Al mismo tiempo, es posible observar que la conformación de redes sociales interpersonales (McAdam, 1982 y 1988; Diani, 2004) tienden a ser claves para el desarrollo de esas carreras militantes. En el caso de Lisandro, su esposa docente; en el de Maite, su vínculo con H.I.J.o.s., cuya principal dirigente es la hija de un militante de ATE desaparecido durante el Terrorismo de Estado en Argentina. Finalmente, en el caso de Martina, su vínculo con la CGT le abre paso dentro del Partido Justicialista. De esta manera, los orígenes de la militancia sindical y los momentos de ruptura de esas trayectorias están marcadas por esas redes, que actúan como facilitadores de esas militancias.

Una diferencia central entre las trayectorias es que Lisandro sostiene en el tiempo su actividad militante dentro del ámbito sindical, pero Martina y Maite mantienen un doble compromiso, estableciendo un proceso de transversalidad o multiposicionamiento, desarrollando militancias en diversos ámbitos de participación (Belardi, 2020). Además, la carrera militante de Lisandro es la que mayores rupturas atraviesa, a mediados de los 90 comienza a organizar un frente interno en ADIUNJu.

ADIUNJu estaba en el proceso de incorporación de los preuniversitarios, entonces con algunos compañeros decidimos 'che, por qué no hacemos una puntita acá, justo en una movilización, estaban haciendo huelga de hambre compañeros, dijimos 'metete' $y$ así empezamos a trabajar en ADIUNJu (Lisandro, comunicación personal, junio de 2015).

Estos cambios fueron leídos por Lisandro como una oportunidad política, abandonó su militancia en C.E.D.E.M.I.S. y se integró de lleno en ADIUNJu, donde a fines de los 90 su frente ganó las elecciones y asumió como Secretario General. Hasta ese momento, el relato de Lisandro muestra grietas, desvíos y dudas, pero su mirada cambia cuando hace referencia a su lugar en $A D I U N J u$, que es presentada como el logro más importante de su carrera militante.
Estoy desde el ' 99 al frente del sindicato, [y] hemos logrado crecer como asociación, hemos logrado crecer como federación, hemos logrado sumar a la lucha a muchos compañeros, nos hemos sumado a la lucha de las organizaciones de Derechos Humanos y sociales desde siempre, sin ningún tipo de restricción política, [...] hemos blanqueado el sueldo, tenemos la jubilación móvil con el $82 \%$, conseguí el convenio colectivo de trabajo, tenemos personería en el gremio (Lisandro, comunicación personal, junio de 2015).

Lisandro se adjudica los logros del gremio, pero al mismo tiempo afirma que la lucha debe ser colectiva y que tiene que servir de experiencia para los jóvenes militantes. Por otro lado, desde su mirada, la militancia sindical no puede estar separada de las luchas sociales, el sindicalismo debe acompañar las demandas de los sectores populares, principalmente porque los trabajadores estatales representan, en Jujuy, el núcleo fundamental de la movilización social:

Nosotros [por ejemplo] ayudamos a los organismos de Derechos Humanos, compartimos consignas. [Estuvimos] con Kike Mosquera acá en El Triángulo ${ }^{10}$ [...] yo siempre trato de ayudar al que puedo ayudar. (Lisandro, comunicación personal, junio de 2015).

Caso contrario es la carrera de Martina, donde su militancia se desarrolló a partir de su doble compromiso político y el involucramiento a la práctica político-partidaria. Los vínculos generados a partir de su actividad gremial y partidaria se configuraron como clave para armar una lista para comisionados de Purmamarca por el Partido

10 Hace referencia a las tomas de tierras en la localidad de Libertador General San Martín. Esos terrenos, propiedad de la empresa Ledesma, fueron ocupados por militantes de la ccc, que fueron violentamente reprimidos. Sobre este tema ver Berardi (2017). 
Justicialista e integrar ese espacio, pero esa experiencia no fue la esperada:

En Purmamarca se eligen comisiones municipales, entonces habíamos armado, [una lista], el vecino de Purmamarca me fue conociendo, cuando se enteraron que estaba en la lista [dentro del PJ] estaban re contentos y decían que iban a apoyar la lista nuestra, qué pasó, [...] ellos [PJ] te imponían los candidatos [...] finalmente no pudimos competir. (Martina, comunicación personal, septiembre de 2016).

A pesar de esta desilusión "política", Martina continuó su militancia partidaria, pero siempre por afuera de su actividad gremial, sabiendo de los vínculos y solidaridades que esta puede producir. A diferencia de Lisandro, para ella el sindicalismo puede resolver los problemas de las personas trabajadoras y defender sus derechos, pero es a través de los espacios partidarios donde es posible ayudar a cambiar la vida de las personas sin importar dónde trabajan, si son jubilados o trabajadores independientes. Ella justifica su involucramiento partidario de la siguiente manera:

No quería involucrarme mucho en lo político, porque lo mío es más lo gremial, pero en ese momento era necesario porque teníamos que tener llegada al gobierno y estar con el gobierno; porque si vos querías un programa de casas, teníamos que estar. (Martina, comunicación personal, septiembre de 2016).

Además de que su carrera presenta menos puntos de quiebres o contingencias que la de Lisandro, también su estrategia como militante sindical es diferente. Para ella, la militancia sindical no es un espacio a partir del cual cambiar la realidad, en todo caso constituye un lugar de reconocimiento público que le permite acceder a otros espacios de participación: "Me querían agarrar, ponerme para diputada en un momento, porque decían vos conocés toda la gente afiliada de panaderos, te conocés toda la provincia, de Purmamarca también te conocen de UTEDYc, tenés..., o sea, tenés gente". (Martina, comunicación personal, septiembre de 2016).

En el caso de Maite, su práctica militante se acerca mucho más a la perspectiva de Lisandro $y$ al rol de la lucha sindical como fuerza de transformación. Pero, la militancia sindical también constituye un instrumento para acceder a derechos y a cambiar las condiciones de vida, pero desde una "lucha" colectiva y por eso ella reivindica las palabras de Raúl cuando sostiene: "Se trata de poner el cuero, por lo que uno cree, hay que poner el cuerpo para pelear, [...] y vos no ganás si no peleás." (Raúl, comunicación personal, junio de 2015).

Para Maite es fundamental que los trabajadores conozcan sus derechos, la protesta por sí sola no funciona si no se puede trasmitir cuáles deberían ser las condiciones de trabajo adecuadas. El empleo estatal en Jujuy, según ella, está plagado de condiciones de trabajo precarias, abusivas y violentas, por eso también aceptó ser delegada en cada uno de los espacios laborales que integró. Maite sostiene que el delegado encuentra la oportunidad de construir una relación con los trabajadores con el fin de ayudar a resolver sus problemas dentro del ámbito laboral y garantizando su representación en caso de conflictos.

La militancia sindical, en este sentido, es mirada desde una idea de lucha contra el atropello a los derechos, a la coerción sobre los trabajadores, a la injusticia y así lo reafirma Beatriz, militante sindical integrante de la comisión directiva del Sindicato de Comercio Seccional Jujuy:

[la militancia sindical tiene que ver con] no dejarte atropellar, no dejarte pisotear, que te escuchen. El objetivo es tus derechos, no tener miedo, sobre todo que nadie te haga sentir ese temor, que no tengas que ir enfermo a trabajar porque tenés miedo de quedarte sin trabajo. (Beatriz, comunicación personal, septiembre de 2016). 
Así, la violación de los derechos laborales $y$ el desconocimiento de estos por parte de los trabajadores son razones del compromiso de Maite en la militancia sindical, pero además el espacio de pertenencia es clave. ATE para ella no solo es el gremio que se compromete con los trabajadores, no solo es el más grande, sino también el más combativo y el que está siempre en la calle defendiendo a los "laburantes".

Los laburantes que están más cagados saben dónde van a ir cuando tienen que pelear, acá en Jujuy [...] hay un montón de sindicatos, pero saben que para pelear van a ATE digamos, porque es el gremio que sale a la calle y que se pone a organizarse [...], ya sea por un solo trabajador o por 10, [de los gremios que hay] solo ATE crece. (Maite, comunicación personal, junio de 2015).

En el año 2015, Maite fue electa secretaria de Comunicación en ATE Jujuy y comenzó a formar parte de la Central de Trabajadores Argentinos Jujuy también como secretaria de Comunicación. Desde su lectura, llegar a esos lugares es una responsabilidad y representa el compromiso asumido para con sus compañeros que le dan esa confianza: "además de una responsabilidad muy grande, un reconocimiento al laburo." (Maite, comunicación personal, junio de 2015).

\section{CONCLUSIONES}

Este artículo se propuso analizar la militancia sindical a partir de la perspectiva de carrera, con el objetivo de dar cuenta de los elementos que determinan un tipo de compromiso político sindical, mostrando las continuidades $y$ rupturas en cada una de las trayectorias.

A partir de comprender las condiciones de inicio, los procesos de aprendizaje $y$ el desarrollo de las prácticas políticas de tres militantes sindicales de la provincia de Jujuy, reconstruyendo cada una de las secuencias 0 etapas, este trabajo permitió observar que, a pesar de estar condicionada por la actividad laboral de los sujetos, la militancia sindical no es idéntica para todos. La organización de pertenencia y la experiencia con el entorno tienen un peso clave en el desarrollo de la carrera militante, pero es posible identificar secuencias comunes en los tres militantes.

Entonces, si bien no es posible establecer generalidades a partir de los resultados de este artículo, sí se puede afirmar que el recorrido de cada una de las carreras es diverso, a pesar de que en cada una de ellas haya continuidades o factores en común.

En este caso, el análisis de gremios que tienen un vínculo directo permitió observar el impacto de la práctica sindical en el proceso individual de compromiso, fundamentalmente, si se observa que los 3 militantes inician sus carreras en décadas diversas, pero son contemporáneos en los años 2000.

Por otro lado, se destaca que los 3 militantes comparten experiencias previas como acceso a la socialización política y que dos de ellos (justamente mujeres) establecen un doble compromiso político o multiposicionamientos.

También, es posible destacar que uno de militantes analizados, Maite, mantiene su militancia sindical, incluso, cuando ya no forma parte del espacio laboral de pertenencia. Este elemento resulta clave, principalmente porque permite afirmar que los estudios microsociológicos, como el que propuso este artículo, facilitan la exploración de elementos que serían desestimados en estudios macroestructurales, como un activismo sindical más allá de la pertenencia a una actividad laboral asociada al gremio.

Al mismo tiempo, en cada una de las carreras militantes se pudo ver discontinuidades $y$ rupturas (o hitos), y si bien, los tres militantes alcanzaron lugares de conducción, Maite y Martina desarrollaron sus carreras en el mismo sindicato, pero no Lisandro.

En este punto es fundamental la estrategia política en cada uno de los espacios de pertenencia y la forma en que las estructuras actúan como elementos persuasivos de la acción militante. En el caso de Lisandro y Maite, esos elementos, la pertenencia a gremios con experiencia protestas y movilización, son factores motivacionales, pero también coercitivo de su compromiso. 
La movilización y la protesta, en el caso de Lisandro y Maite, figuran como espacio de intercambio, socialización y estrategia política en el sentido amplio; mientras que para Martina es la militancia partidaria la que determina ese tipo de estrategia. Así, se observa que hay una diferenciación entre la militancia política, por un lado, la sindical $y$, por el otro, la partidaria, que si bien se complementan, para Martina no se mezclan.

El estudio de la carrera militante sindical dio cuenta que si bien hay factores comunes que se repiten en las trayectorias, las singularidades parecen no estar condicionadas solo por los contextos, sino también por la manera en que las organizaciones sindicales se presentan a la disputa política y gremial, lo que influye en las decisiones que toman sus militantes, mostrando más singularidades que generalidades.

\section{REFERENCIAS}

Abal Medina, P. (2011). La correa despolitizadora del sindicalismo empresarial. Un abordaje sobre el colectivo de delegados del supermercado Coto en la Ciudad de Buenos Aires. Apuntes de investigación del CECYP, (20), 65-92.

Abal Medina, P. (2015). Dilemas y desafíos del sindicalismo argentino. Las voces de dirigentes sindicales sobre la historia política reciente. Trabajo y Sociedad, (24), 53-71.

Abal Medina, P. (2016). Los trabajadores y sus organizaciones durante los gobiernos kirchneristas. Nueva Sociedad (264), 72-86.

Agrikoliansky, E. (2017). Les 'carrières militantes'. Portée et limites d'un concept narrative. En O. Fillieule, F. Haegel, Ca. Hamidi y V Tiberj (Coord.), Sociologie plurielle des comportements politiques (pp. 167-192). Presses de Sciences Politiques.

Anigstein, C. (2019). De la articulación orgánica a la confrontación: la CGT y los Gobiernos kirchneristas en la Argentina. Cahiers des Amériques latines, (90), 141-159.

Aramayo, B. (2009). Jujuy en el bicentenario. Contexto e historia de luchas. Editorial Ágora.
Armelino, M. (2004). Algunos aspectos de la acción colectiva y la protesta en la CTA $y$ el MTA. Lavboratorio, (15), 5-11.

Armelino, M. (noviembre de 2005). La protesta sindical en la Argentina de los años noventa. [Ponencia] viI Congreso Nacional de Ciencia Política, Sociedad Argentina de Análisis Político, Ciudad de Córdoba, Córdoba, Argentina.

Armelino, M. (2012). Kind of blue. Las vicisitudes de la Central de Trabajadores de la Argentina (CTA) durante los años kirchneristas. En G. Pérez y A. Natalucci. (Ed.), Vamos las bandas. Organizaciones y militancia Kirchneristas (pp. 101-126). Nueva Trilce.

Becker, H. (2012). Outsider. Siglo xxI Editores.

Berardi Spairani, A. P. (2017). El mundo militante en la democracia argentina contemporánea: un estudio de trayectorias militantes en la provincia de Jujuy. [Tesis de Doctorado en Sociología]. Instituto de Altos Estudios Sociales, Universidad Nacional de San Martín.

Berardi Spairani, A. P. (2020). La transversalidad militante y la participación política. Revista Mexicana de Sociología, 82(3), 645-672.

Bergesio, L. y Golovanevsky, L. (2010). Ferroviarios y zapleros en Jujuy: de la seguridad social a la inestabilidad laboral. Revista de Estudios Regionales, (6), 7-42.

Belli, E. y Slavutsky, R. (1996). La modernidad Agrietada. Los Procesos Políticos en Jujuy. Instituto interdisciplinario de Tilcara, Facultad de Filosofía y Letras. Universidad de Buenos Aires.

Berengan, M. (noviembre de 2013). El cabildo abierto y los límites del proceso. Logros y derrotas de la rebelión de 1990. [Ponencia] I Congreso Internacional de Ciencias Sociales y Humanidades Universidad Nacional de Córdoba. Ciudad de Córdoba, Argentina.

Della Porta, D. (2014). Methodological Practices in Social Movement Research. Oxford University Press.

Diani, M. (2004). Networks and Participation. En D. Snow, S. Soule y H. Kriesi (Ed.), 
The Blackwell Companion To social movements (pp. 339-359). Blackwell Publishing Ltd.

Etchemendy, S. y Collier, R. (2008). Golpeados pero de pie. Resurgimiento sindical y neocorporativismo segmentado en Argentina (2003-2007). Postdata, (13), 145-192.

Ferrari, F. (2014). Cambios en el modo de acumulación y articulación de las resistencias. Trabajadores ocupados y trabajadores desocupados en Jujuy durante la década de 1990. En G. Galafassi (Comp.), Apuntes de acumulación: capital, estado y procesos sociohistóricos de reproducción y conflictividad social (pp.165-180). Extramuros Ediciones.

Ferrari, F. (2018). La precarización como categoría nativa: exploraciones en torno al trabajo público municipal en Jujuy, noroeste de Argentina. Revista Latinoamericana de Antropología del trabajo, 2(3).

Fillieule, O. (2001). Propositions pour une analyse processuelle de l'engagement individuel. Revue française de science politique, (51), 199-215.

Fillieule, O. y Tartakowsky, D. (2015). La Manifestación. Cuando la acción colectiva toma las calles. Siglo XXI.

Gómez, E. y Kindgard, F. (2002). Los cortes de ruta en la escala de luchas de los obreros jujeños. PIMSA, (5), 113-131.

Gómez, E. y Kindgard, F. (2006). Trabajo, desocupación y movimiento Obrero. En A. Teruel, y M. Lagos (Dir.), Jujuy en la historia: de la colonia al siglo XX (pp. 519549). EDIUNJU.

Gordillo, M. (2013). Normalización y democratización sindical: repensando los '80. Desarrollo Económico, 53(209/210), 143-167.

Iñigo Carrera, N. y Gómez, E. (2011). Las organizaciones político-sindicales de los asalariados estatales organizan la lucha de los desocupados: Jujuy, 1994-2004. En N. Iñigo Carrera (Dir.), Sindicatos y desocupa dos en Argentina. 1930/19351994/2004: cinco estudios de caso (pp. 117-177). PIMSA/Dialektik.
Kindgard, F. (2009). Los conflictos sociales bajo la era neoliberal. En M. Lagos (Coord.), Jujuy Bajo el signo Neoliberal. Política, Sociedad y cultura en la década del noventa (pp. 311-355). EDIUNJu.

Kindgard, F. y Gómez, E. (1998). Los cortes de ruta en la provincia de Jujuy. Documento de Trabajo $N^{o}$ 15. Programa de Investigación sobre el Movimiento de la Sociedad Argentina.

Klandermans, B. (1984). Mobilization and participation in trade union action: An expectancy-value approach. Journal of Occupational Psychology, (57), 107-120.

Lagos, M. y Gutiérrez, M. (2006). Dictadura, democracia y políticas neoliberales 1976 1999. En A. Teruel, y M. Lagos (Dir.), Jujuy en la historia: de la colonia al siglo XX (pp. 234-294). EDIUnJu.

Lagos, M. y Conti, V. (2010). Jujuy de la revolución de mayo a nuestros días. EDIUNJu.

Marticorena, C. (2015). Avances en el estudio de la relación entre sindicalismo y kirchnerismo. Sociohistórica (36).

McAdam, D. (1982). Political process and development of black isurgency, 1930-1970. The University of Chicago Press.

McAdam, D. (1988). Freedom summer. Oxford University Press.

Meccia, E. (2012). Subjetividades en el puente. El método biográfico y el análisis microsociológico del tránsito de la homosexualidad a la gaycidad. Revista Latinoamericana de Metodología en Investigación Social, (4), 38-51.

Meccia, E. (2015). Cambio y narración. Las transformaciones de la homosexualidad en Buenos Aires según los relatos de homosexuales mayores. Sexualidad, Salud y Sociedad, (19), 11-43.

Murillo, M. V. (2013). Cambio y continuidad del sindicalismo en democracia. SAAP, 7(2), 339-348.

Natalucci, A. (2013). Revitalización sindical $y$ sindicalismo peronista: encrucijadas entre el corporativismo y la política (Argentina, 2003-2012). Amérique Latine Histoire et Mémoire. Les Cahiers ALHIM, 26. 
Oszlak, O. (1997). Estado y sociedad: ¿nuevas reglas de juego? reforma $y$ democracia. CLAD, 9 .

Palomino, H. (2000). Los sindicatos en la Argentina contemporánea. Nueva Sociedad (169), 121-135.

Palomino, H. (2005). Los cambios en el mundo del trabajo y los dilemas sindicales. En J. Suriano (Dir.), Nueva Historia Argentina tomo X. Dictadura y democracia (19762001) (pp. 377-443). Sudamericana.

Passy, F. (2002). Social Networks Matter. ButHow? En M. Diani, y D. McAdam (Eds.), The Social Movement and networks: Relational Approach to collective action (pp 21-48). Oxford University Press.

Pereyra, S. (2008). ¿La Lucha es una sola? Ediciones UNGS/ Biblioteca Nacional.

Rodríguez Blanco, M. (2002). La parte de los que no tienen parte: La dimensión simbólica y política de las protestas sociales: la experiencia de los piqueteros en Jujuy. Cuaderno de Trabajo $N^{o} 10$. Departamento de Ciencias Sociales, Centro Cultural de la Cooperación.

Saltalamacchia, H. (1987). Historia de vida y movimientos sociales: el problema de la representatividad (apuntes para la reflexión). Revista Mexicana de Sociología 49(1), 255-277.

Schorr, M. y Golovanevsky, L. (julio de 2012). Estructura productiva, distribución del ingreso y subdesarrollo. El círculo vicioso de la pobreza en Jujuy en la primera década del siglo XXI. [Ponencia] I Jornadas Nacionales sobre Estudios Regionales y Mercados de Trabajo. Santa $\mathrm{Fe}$, Argentina.

Schneider, A. (2013). Del alfonsinismo al kirchnerismo. El movimiento obrero bajo la democracia (1983-2012). En M. Burkart y M. Giletta (Ed.), Dossier Argentina: 30 años de democracia, Observatorio latinoamericano (12), 222-233.

Varela, P. (2013). El sindicalismo de base en la Argentina posconvertibilidad. Hipótesis sobre sus alcances y potencialidades. En J. Grigera (comp.), Argentina después de la convertibilidad (2002-2011) (pp. 115 -289). Imago Mundi.

Varela, P. y Lotito, D. (2009). La lucha de KraftTerrabusi. Comisiones Internas, izquierda clasista y "vacancia" de representación sindical. Conflicto Social, 2(2), 256-291.

Vázquez, M. (2010). Socialización política y activismo. Carreras de militancia política de jóvenes referentes de un movimiento de trabajadores desocupados. [Tesis de Doctorado en Ciencias Sociales]. Universidad de Buenos AiresFacultad de Ciencias Sociales.

Fecha de ingreso: 17/09/2020 Fecha de aprobación: 14/10/2021 